\title{
EDUCAÇÃO SEXUAL PARA ALUNOS/AS COM DEFICIÊNCIA EM PORTUGAL: INDÍCIOS DE UMA FORMAÇÃO DOCENTE PRECÁRIA ${ }^{1}$
}

\author{
SEXUAL EDUCATION FOR STUDENTS WITH DISABILITIES IN PORTUGAL: \\ INDICATIONS OF PRECARIOUS TEACHING TRAINING
}

\begin{abstract}
Ana Cláudia Bortolozzi Maia ${ }^{1}$, Leilane Raquel Spadotto de Carvalho² e Teresa Vilaça ${ }^{3}$
1 Professora Livre Docente do Departamento de Psicologia, Faculdade de Ciências. Universidade Estadual Paulista “Júlio de Mesquita Filho”, Brasil. e-mail: claudia.bortolozzi@unesp.com

2 Mestranda em Psicologia do Departamento de Pós-Graduação da Faculdade de Ciências, Universidade Estadual Paulista "Júlio de Mesquita Filho", Brasil. e-mail: leilane.spadotto@hotmail.com ${ }_{3}^{3}$ Professora Auxiliar do Departamento de Estudos Integrados de Literacia, Didática e Supervisão. Instituto de Educação. Universidade do Minho-UM. Portugal. e-mail: tvilaca@ie.uminho.pt
\end{abstract}

\author{
ARTICLE INFO \\ Article history: \\ Received 2020-02-10 \\ Accepted 2020-02-20 \\ Available online 2020-02-20
}

Palavras-chave: Educação Sexual. Deficiências. Formação de Professores.

Keywords: Sexual Education. Disabilities. Teacher training.

RESUMO. A Educação Sexual nas escolas é lei em Portugal, mas as especificidades dos (as) alunos (as) com deficiências são, poucas vezes, consideradas nas propostas educativas. Este estudo qualitativo descritivo teve por objetivo investigar as opiniões, sentimentos e ações sobre a Educação Sexual para alunos (as) com deficiência, de dez professores portugueses, sendo 7 mulheres e 3 homens, atuantes do $3^{\circ}$ ciclo escolar ( $7^{\circ}$ ao $9^{\circ}$ ano de escolaridade). Os (as) professores (as) participaram de uma entrevista, gravada e transcrita na íntegra, para análise de conteúdo, evidenciando as dificuldades na formação, a partir das categorias que desvelam que os (as) professores (as): (a) não compreendem a Educação Sexual nas suas salas de aula como parte de um trabalho pedagógico de toda a escola; (b) têm receio dos familiares dos (as) alunos (as) e desconhecem as condições e recursos necessários às especificidades de seus (as) alunos (as) com deficiências e (c) reconhecem a necessidade de cursos na formação inicial e continuada sobre sexualidade, principalmente para alunos (as) com deficiência. Conclui-se que é fundamental garantir a formação docente na área da sexualidade e educação para o público da educação especial, para garantir a eficácia da lei em Educação Sexual nas escolas inclusivas de Portugal.

ABSTRACT. Sexual Education in schools is law in Portugal, but the specificities of students with disabilities are rarely considered in educational proposals. This qualitative descriptive study aimed to investigate the opinions, feelings and actions on Sexual Education for students with disabilities, of ten Portuguese teachers, 7 women and 3 men, working in the 3rd school cycle (7th to 9th grade)). The teachers participated in an interview, recorded and transcribed in full, for content analysis, showing the difficulties in training, from the categories that reveal that the teachers: (a) do not understand Sexual Education in their classrooms as part of a school-wide pedagogical work; (b) are afraid of the students' relatives and are unaware of the conditions and resources necessary to the specificities of their students with disabilities; and (c) recognize the need for courses in initial and continuing training on sexuality, especially for students with disabilities. We conclude that it is essential to guarantee teacher education in the area of sexuality and education for the special education public, in order to guarantee the effectiveness of the law in Sexual Education in inclusive schools of Portugal.

\footnotetext{
${ }^{1}$ Resultados parciais da Pesquisa financiada pela Fapesp (Processo 2016/14382-0).
} 


\section{Introdução}

A Educação Sexual nas escolas em Portugal é lei desde 2009, seguindo uma tendência europeia de respeitar as recomendações de órgãos internacionais que defendem as escolas promotoras de saúde, tais como a Organização Mundial da Saúde e a UNESCO. (VILAÇA, 2013).

A Educação Sexual é um processo amplo no qual aprende sobre sexualidade seja de modo informal, assistemático e em diferentes instâncias sociais, como a família, a escola, os meios de comunicação, os discursos religiosos, artísticos, etc. Dentro deste aspecto educativo amplo - consideramos um modelo pedagógico específico, a Educação Sexual Intencional, em geral, formal e sistematizada, quando nela há um programa ou ações didáticas com objetivos e metas definidas (MAIA; VILAÇA, 2019a; MATOS et al, 2014; UNESCO, 2014). Por exemplo, a elaboração e a realização de um programa de prevenção ao contágio de HIV/aids, prevenção contra a gravidez na adolescência, um programa que ofereça informações sobre o corpo humano e a puberdade, um programa que discuta as violências de gênero, preconceitos decorrentes, etc.

Autores têm evidenciado a grande contribuição no desenvolvimento de crianças e jovens sobre a existência da Educação Sexual nas escolas (MAIA; RIBEIRO, 2011; UNESCO, 2014); entretanto, ainda é complexo pensar no (a) educador (a) responsável por esse processo (MAIA; RIBEIRO, 2011; VILAÇA, 2017; RIBEIRO, PONTES; SANTOS, 2013). Estará o (a) professor (a) preparado tecnicamente e academicamente para essa função? Sua formação garante a possibilidade de um bom processo de transmissão de informação sem que seus valores pessoais, morais e religiosos atravessem essa temática? Já dissemos outrora que:

Estudos a nível internacional mostram que as maiores dificuldades dos professores são: receio de que os propósitos dessa educação sejam voltados à vulgaridade, receio da reação dos familiares, falta de habilidades para elaborar e implementar programas de ES, falta de formação e preparo técnico cientifico para fazê-lo e, ainda, dificuldades no plano moral e subjetivo (UNESCO, 2009). As questões subjetivas e os valores pessoais são fortes influências para direcionar as ações de professores diante dos comportamentos sexuais de seus alunos/as, além das escolhas de conteúdos, estratégias e recursos pedagógicos (MAIA; VILAÇA, 2018, p.2).

Nas escolas inclusivas, a Educação Sexual deve ser oferecida e acessível a todas as pessoas, sobretudo, aos alunos e alunas com diferentes condições de desenvolvimento e aprendizagem. Autores como França-Ribeiro (2004), Gesser e Nuerberg (2014) defendem que a Educação Sexual para pessoas com deficiência é um direito que deveria ser assegurado para diminuir as situações de preconceito e vulnerabilidade social. 
Em estudos anteriores (MAIA, 2016; MAIA; VILAÇA, 2019b) temos reiterado que pessoas com deficiência têm a sexualidade inerente, como quaisquer outras pessoas, embora seus comportamentos, decorrentes de condições especificas da deficiencia ou de processos deficitários de educação, possam visibilizar uma ideia de atipia ou "diferença". No caso de deficiência intelectual, podem emitir comportamentos exibicionistas, inadequados, invasivos e arriscados a si mesmos ou aos demais. Pessoas cegas ou surdas são mais expostas às situações de vulnerabilidade por não compreenderem informações de prevenção ou de proteção; também podem se comportar inadequadamente, sobretudo, se não receberem educação sexual. Outras deficiências ou pessoas consideradas público alvo da educação especial ${ }^{2}$, também acabam por ser condições que potencializam o estigma que pesa sobre elas na representação de uma "sexualidade patológica".

A falta de educação sexual e a história de preconceito sobre as pessoas estigmatizadas pela deficiência alimenta a existência de mitos e crenças, tais como: de que elas seriam "assexuadas" e angelicais, que elas seriam "hiperssexuadas" - mostruosas e grotescas, que elas seriam indesejáveis sexualmente, inférteis, incapazes de se envolverem em relacionamentos amorosos e sexuais, etc. (ANDERSON, 2000; KAUFMAN; SILVERBERG;ODETTE, 2003; MAIA; RIBEIRO, 2010; MAIA; VILAÇA, 2009b).

Maia e Vilaça (2019b, p.159), afirmam que

Há dois grandes mitos opostos que frequentemente são explicitados: acreditar que sexualidade das pessoas com deficiência manifesta-se de maneira ausente, angelical, ingênua e infantil - chamada aqui de "assexualidade" ou que ela é aberrante, exagerada, exacerbada, chamada aqui de "hipersexualidade" (...) Por um lado, entender a sexualidade como algo "infantil" é um modo de diminuir o potencial erótico dessas pessoas e não colaborar para o desenvolvimento emocional e social que lhes deem autonomia que se espera na vida adulta. Ainda que alguns comportamentos sexuais das pessoas com deficiência possam ser considerados inadequados, exibicionistas, desregrados e que não correspondem às regras sociais, isso não faz essas pessoas serem desprovidas de sexualidade e/ou terem um corpo ausente de desejos eróticos (...). Por outro lado, entender que a sexualidade das pessoas com deficiência é exagerada e aberrante é uma concepção decorrente da observação de comportamentos grotescos, geralmente ocorridos publicamente e essa visibilidade reforça uma crença de que o desejo sexual é "exagerado" por ser relacionado à deficiência. Mas sabemos que, expostas aos meios educativos sobre a aprendizagem das regras sociais e ao desenvolvimento das habilidades sociais necessárias no convívio, as pessoas com deficiência podem aprender a expressar seus sentimentos e desejos sexuais iguais aos de todos (as) - de um modo socialmente saudável e gratificante (...) As discussões sobre as ideias pré-concebidas que direcionam as atitudes sociais diante da sexualidade das pessoas com deficiência indicam que não são exatamente as condições específicas das deficiências que levam as possíveis dificuldades na vivência da sexualidade, mas as condições sociais que colaboram para essa expressão como, por exemplo, uma deficitária educação sexual (MAIA, VILAÇA, 2019b, p.159).

\footnotetext{
2 Público alvo da educação especial (PAEE) abarca os (as) alunos (as) com deficiência e com Transtornos Globais do Desenvolvimento (TGD), que são aqueles (as) que apresentam alterações psicomotoras, comprometimento de relações sociais, comunicação e habilidades motoras (estereotipia), incluindo Transtorno do Espectro Autista (TEA) e com Altas Habilidades/Superdotação (AH/SD).
} 
Se já é complicado pensar nos (as) professores (as) que atuam na Educação Sexual nas escolas e na formação que recebem (ou não), mais complexa torna-se a questão, quando a escola inclusiva apresenta uma diversidade de alunos e alunas que exigem currículos adaptados e metodologias de ensino alternativos (MAIA; VILAÇA, 2019). Além disso, outros autores ressaltam a necessidade de existirem materiais específicos para que a educação sexual seja inclusiva (ADEREMI, 2014; MAIA; VILAÇA, 2019).

Estudos apontam a falta de preparo e a necessidade de formação dos (as) professores (as) na educação sexual para pessoas com deficiências (ALBUQUERQUE; ALMEIDA, 2010; CHIRAWU et al., 2014; MAIA; ARANHA, 2005; MAIA et al., 2015; MELO, 2007; MELO; BERGO, 2003). E autores como Costa e Ribeiro (2012) e Gesser, Oltramari e Panisson (2015) lembram inclusive dessa necessidade na formação inicial.

Diante dessas considerações, este estudo qualitativo, descritivo e exploratório (SPATA, 2005; SAMPIERI;COLLADO;LUCIO, 2006), teve por objetivo investigar, a partir dos relatos de professores (as) portugueses, suas opiniões, sentimentos e ações sobre a Educação Sexual para pessoas com deficiência na escola inclusiva.

\section{Método}

Todos os procedimentos éticos foram respeitados, sendo o estudo validado pela Comissão de Ética da Universidade do Minho, em Portugal e também autorização pelo sistema de Monitorização de Inquéritos no Meio Escolar, no Ministério de Educação de Portugal (inquérito n.ํ0604200001).

\subsection{Participantes}

Foram participantes dez professores, sendo sete mulheres e três homens, entre 40 e 55 anos, atuando no $3^{\circ}$ ciclo do ensino básico ( $7^{\circ}$ ao $9^{\circ}$ ano de escolaridade) que atuavam do norte de Portugal. Seis tinham a Licenciatura como grau mais elevado de formação e quatro casos de Mestrado/Especialização. As áreas de atuação eram: Línguas: Inglês, Português e Francês ( $n=5)$, Educação Artística, Musical e Esportes ( $n=3)$, Ciências Sociais $(n=1)$, Ciências Biológicas e Geologia $(n=1)$. Todos lecionavam há mais de seis anos.

\subsection{Instrumento/Materiais}

Para a coleta, utilizou-se um roteiro de entrevista, elaborado pelas autoras e previamente validado. Havia questões semiabertas e abertas e tais questões foram organizadas em eixos temáticos relacionados aos objetivos. Tal instrumento foi utilizado na 
integra e parcialmente neste e em outros estudos pelas autoras (DA COSTA; MAIA, 2019; DE CARVALHO; MAIA, 2020).

\subsection{Procedimentos de Coleta e Análise de Dados}

Os (as) professores (as) foram convidados (as) a participar mediante visita pessoal a escolas e convite pessoal em reunião junto aos professores, após esclarecimentos gerais sobre a pesquisa. Aos interessados em participar voluntariamente, agendava-se ao longo do mês seguinte, dia e horário mais conveniente na própria escola em que lecionavam. Foram necessárias três escolas para o total de dez voluntários.

As entrevistas foram realizadas individualmente e gravadas em áudio, com anuência do (a) professor (a). Toda a interação verbal foi transcrita, na íntegra, para a elaboração de categorias temáticas, mutuamente exclusivas, a partir da análise de conteúdo de Bardin (2011). Neste artigo, apresentamos a categoria que indica a precária formação dos professores na área da educação sexual para alunos com deficiências.

\section{Resultados ${ }^{3}$}

Em vários relatos dos professores (as) podemos evidenciar as dificuldades e entraves na Educação Sexual que realizam na escola formalmente ou informalmente, quando se trata de alunos (as) com deficiência ou não.

Nos relatos dos (das) professores, manifestaram-se favoráveis à existência da Educação Sexual nas escolas, porém, relacionando-a a "afetividade" e ao apoio dos familiares e de outros (as) profissionais, sugerindo uma insegurança na atuação individual em suas disciplinas. As categorias desveladas nos relatos dos professores (as) sugerem a precária formação docente:

\subsection{0 (a) professor (a) não compreende a Educação Sexual na sua sala de aula como parte de um trabalho pedagógico de toda a escola.}

É possível perceber que, mesmo favoráveis à Educação Sexual, ela é representada pelo professor (a) como sendo algo "da escola" ou de algumas disciplinas específicas e não como sua função ou sua responsabilidade, mesmo que, eventualmente ele (a) tenha que assumir essa tarefa.

(...) não será o meu papel principal (...) há disciplinas especificas que falam sobre o tema e, digamos, esse é o local próprio e certo para desenvolver o tema com mais qualidade e

\footnotetext{
${ }^{3}$ A apresentação e discussão desses dados parciais - organizados em subcategorias - foram realizadas no evento VII Seminário Corpo, Gênero e Sexualidade, do III Seminário Internacional Corpo, Gênero e Sexualidade e do III Luso-Brasileiro Educação em Sexualidade, Género, Saúde e Sustentabilidade, 2018, Rio Grande, RS. Ver: MAIA e VILAÇA (2018).
} 
com orientações certas; (...) todos nós temos que, de certa forma, fazer alguma educação... (P4)

Não é o meu papel, nem tenho formação cientifica no assunto, mas sempre que me fazem alguma pergunta, dou a minha opinião (...). Não tenho preparação, mas acho que não teria problema de trabalhar nessa área (P9).

De qualquer forma, não foi citado, por nenhum professor, apesar da Educação Sexual existir na escola como recomendação legal, que a Educação Sexual ocorria na instituição como parte de um projeto elaborado, inserido na proposta curricular e pedagógica, com objetivos e princípios definidos, e sim como intervenções diante de situações específicas e com finalidades de "controle" e "correção", como podemos ver no relato de P4 que destaca que suas intervenções seriam no sentido de "corrigir comportamentos desviantes" dos alunos, sugerindo as finalidades de sua atuação.

(...) quando é preciso intervir. Agora, a nível de programa, de currículo, sabemos que não, não acontece. (...) tive duas ou três aulas, para falar sobe isso (...) mas não era uma intervenção, digamos, a médio prazo. Se tivesse que intervir porque havia situações que não eram as mais corretas, intervinha só naquela altura (P6).

\subsection{0 (a) professor (a) tem receio dos familiares dos alunos (as) e desconhece as}

\section{condições e recursos necessários às especificidades de seus (as) alunos (as) com deficiências}

Já sobre a educação sexual para os (as) alunos (as) com deficiência, houve aqueles (as) que alegaram que não havia nada na escola voltado especificamente aos alunos (as) com deficiência ou pensando neles (as) e outros professores (as) afirmam que eles (as) recebiam informações sobre sexualidade, quando essas eram oferecidas aos (as) demais alunos (as).

Nós tivemos em parceria com o grupo de ciências naturais, uma sessão sobre sexualidade, a saúde para a sexualidade e eu levei os meus meninos, juntamente com outra professora, mas a minha turma esteve muuuito atenta, incluindo o $A$ [nome próprio] que é o menino que veio da Educação Especial. [com deficiência intelectual] (...) estava constantemente a colocar perguntas...

Houve um projeto que era a nível nacional, mas acho que aquilo, como começou, parou, nada específico para eles [alunos(as) com deficiências] (P9F)

Quando os (as) professores (as) têm que assumir a educação sexual, alguns (as) têm receio do que os (as) alunos (as) irão contar às famílias ou interpretar sobre o que falam sobre sexualidade e assumem que o assunto é um pouco constrangedor, evidenciando, novamente, insegurança por parte dos professores (as) em suas ações. 
(...) as vezes coincide com um tema qualquer em sala de aula que temos que ter muito cuidado (...) na aula eles reagem bem, normal, mas (...) o meu maior medo é... o que eles levam para casa... se dizem exatamente aquilo (...) que Ihes foi dito, ou se extrapolam, se inventam por maldade, ou não, ou as vezes até por não conseguiram exprimir aquilo que ouviram...(...) claro, no dia seguinte, estão lá os pais a pedirem explicações (risos) (P1).

(...) na sala de aula ou nas aulas de cívica, eu sinto, às vezes, algum tipo de constrangimento, dependendo do tipo de aluno, que tem sempre aquele que coloca a questão de uma forma mais malandreca, ou que sabe mais que os outros (...) e isso causa um certo desconforto, não vou negar. (...)

(...) são miúdos, falam do jeito que querem, tenho receio como as coisas possam ser interpretadas, não tenho problema nenhum em falar, mas depende do contexto. (...) é muito complicado, falar assim de iniciativa própria (...) como vão interpretar, o que vão levar para casa, como poderiam reagir (P5).

P3 considera que pode constranger o aluno com deficiência $(A c D)$ ao falar do assunto, o que supõe a sua crença de que ele seja "assexuado" ou "diferente" dos demais, mostrando desconhecimento sobre a condição do AcD: "Para esses meninos [com deficiência], ãh... seria pior porque como eu iria abordar a questão sem... sem fazer com que eles se sintam desmoralizados diante dos colegas?. (...) é complicado! (P3)"

Além da insegurança, outras dificuldades e necessidades foram levantadas pelos professores caso atuassem na educação sexual para pessoas com deficiência: a necessidade da colaboração de profissionais de saúde, seja pela dificuldade diante da pouca idade dos/as alunos/as, seja pela falta de conhecimento específico e biológico. Em alguns casos, também foram citados os materiais adequados necessários, como se observa nos extratos seguintes:

Mas, claro, eu também preciso da ajuda da profissional da saúde, porque primeiro estamos a falar de crianças de 12 a 14 anos e... nem tanto ao mar, nem tanto à terra e $2^{\circ}$ (...) se houver alguma coisa biológica, também não sei responder... (...) preciso estar com um professor com bastante formação e de preferência com alguém do ensino de saúde, ou uma enfermeira ou médico..., ou então, alguém do serviço de psicologia da escola, nunca sozinha $(P 1)$.

Eu sinto-me preparada para as perguntas mais básicas, talvez uma ou outra mais profunda, mas agora se me perguntam algo por parte da biologia mesmo, claro que eu vou dizer "não sei, amanhã digo-te", vou falar com as pessoas com quem eu devo me informar e depois digo. Depende sempre dos alunos, (...) da faixa etária... mas não tenho grandes problemas em falar (...) ás vezes não há vídeos, não há...muito material disponível nem adaptados aos deficientes, é aí que às vezes há mais dificuldade... mas acho que faz parte de todos os professores (P2).

\subsection{O (a) professor (a) reconhece a necessidade de cursos na formação inicial e continuada sobre sexualidade, principalmente para alunos com deficiência.}

Questões estruturais, como a Educação Sexual como um projeto na escola, o apoio de dirigentes e familiares, recursos e materiais pedagógicos são importantes no trabalho do 
professor (a) que vai atuar na Educação Sexual na instituição. Entretanto, uma formação sólida, constantemente atualizada e voltada ao contexto em que atua também é fundamental para o sucesso do trabalho de um educador. Lacunas na formação inicial e continuada para atuarem na Educação Sexual, sobretudo com os (as) AcD, foi relatada pelos (as) professores (as), também como um entrave para o desenvolvimento da educação sexual na escola inclusiva:

Eu fiz formação em Letras e nada me preparou para lidar com a sexualidade na sala de aula. Por isso, o erro já vem de cima, deveríamos ter essa formação na universidade e depois receber uma formação nas escolas (P1).

(...) eu sai da universidade em 94 e isso não fazia parte do nosso currículo... tudo que fazemos hoje em dia é por pesquisa nossa (...) não podemos estagnar no tempo (P2).

(...) já fiz várias formações sobre educação sexual (...) é curioso, que essa questão nunca foi abordada. Se me dissesse assim: 'no próximo ano você terá um aluno autista e um com distrofia e vai ter que dar Educação Sexual'... Falta formação! Sem dúvida (P3).

Precisaria de formação, formação, claro. Acho que aqui há áreas que são importantes específicas e técnicas do ponto de vista do conhecimento que eu não trabalho no meu dia a dia, não é? E, nesse sentido, teria que ter uma formação bem orientada, para poder estar a altura de poder responder bem um projeto dessa natureza $(P 4)$.

Os relatos dos (as) professores (as) deste estudo evidenciam concepções favoráveis sobre a educação sexual nas escolas, para todos (as) os (as) alunos (as), mas também dificuldades pessoais e formativas para realizá-la, mesmo nas escolas em Portugal em que a Educação Sexual é prevista legalmente, dados discutidos a seguir.

\section{Discussão}

A formação de professores (as) na área da educação sexual é uma discussão importante na literatura e em um país em que há uma lei que prevê a Educação Sexual nas escolas, seria de se esperar que os (as) professores (as) estivessem mais preparados compreenderem e atuarem nesse processo em suas práticas profissionais, mas não foi o que observamos nesta pesquisa.

Embora seja um estudo qualitativo e sem generalização de dados, os relatos indicam uma fragilidade percebida nos (as) próprios (as) professores (as) que reconhecem a Educação Sexual como necessária, mas nem sempre como sua função, sua possibilidade e ou sua capacidade. Nem ao menos percebem que estão a educar o tempo todo, mesmo que não intencionalmente. 
Os (as) professores (as) entrevistados relataram ações em Educação Sexual pontuais em suas salas de aula e não a participação em um projeto curricular e pedagógico da escola como um todo, como defendem Maia e Ribeiro (2011), Ribeiro, Pontes e Santos (2013) e Vilaça (2017).

Prevaleceram o receio e a insegurança do que fazem. Temem o julgamento de familiares e sentem desconforto para falar sobre sexualidade com os (as) alunos (as).

O quadro fica ainda mais complexo quando pensamos nos (as) alunos (as) com deficiência (MAIA; ARANHA, 2005; MAIA et al, 2015), pois aí, os (as) professores (as) reconhecem que são despreparados, que necessitam do auxílio de profissionais ou de materiais específicos, assim como observaram outros pesquisadores (ADEREMI, 2014; MAIA, et. al.; 2015; WILKENFELD; BALLAN, 2011).

Em síntese, pode-se dizer que as atitudes diante da educação sexual para alunos (as) com deficiência na escola seriam, segundo os (as) participantes: receio e constrangimento diante dos familiares e respostas pontuais à demanda. Se fosse necessário, alguns (as) professores (as) assumiriam a educação sexual, sentindo-se preparados (as) e outros (as) mais inseguros, apontando que suas atitudes tinham relação com a precária formação inicial e continuada na área da educação sexual para pessoas com deficiência, ressaltando a importância da temática na formação docente (ALBUQUERQUE; ALMEIDA, 2010; MAIA et al., 2015; MAIA;VILAÇA, 2017; VILAÇA, 2017).

\section{Considerações Finais}

Os dados apresentam, em consonância com a literatura consultada, que a Educação Sexual para alunos (as) com deficiência na escola esbarra em obstáculos do (a) professor (a) que o (a) educa, tais como: receio por parte dos (as) professores (as) de se constranger e/ou constrangerem os (as) alunos (as) ao abordar a temática; reação e repercussão dos familiares dos (as) alunos (as) e ações pontuais quando o assunto emerge - como responder perguntas individuais (não havendo elaboração de ações planejadas e adaptadas), necessidade de haver profissionais da saúde ou materiais na escola, etc.

Pode-se dizer que só a lei não basta, nem que haja Educação Sexual efetiva nas escolas, muito menos que ela garanta seu alcance a todos (as) os alunos (as), como preveem as prerrogativas da educação inclusiva, por isso, mais uma vez, reiteramos a necessidade de investimentos profundos no campo cientifico da sexualidade no desenvolvimento humano, na formação docente, sobretudo, àqueles que atuarão nas escolas promotoras de saúde.

\section{Referências}


ADEREMI, T. J. Teachers' perspectives on sexuality and sexuality education as learners with intellectual disabilities in Nigeria. Sex Disability, v.32, p.247-258, 2014.

ALBUQUERQUE, P.P.; ALMEIDA, M.A. Sexualidade e deficiência intelectual: um curso de capacitação de professores. Rev. Bras. Estud. Pedagog., v. 91, p.408-423, 2010.

ANDERSON, O. H. Doing what comes naturally? Dispelling myths and fallacies about sexuality and people with developmental disabilities. Illinois: High Tide Press, 2000.

BARDIN, L. Análise de conteúdo. (Tradução de Luis Antero Reto e Augusto Pinheiro). Lisboa: Edições 70, 2011.

CHIRAWU, P.; HANASS-HANCOCK, J.; ADEREMI, T. J.; REUS, L.; HENKEN, A. A. Protect os emable? Teachers1 Beliefs and Practices Regarding Provisiono f Sexuality Education tom leatners with Disability in KwaZulu-Natal, South Africa. Sex Disabil, v. 32, p. 259277, 2014.

DE CARVALHO, L. R. S.; MAIA, A.C. B. Sexualidade, Educação Sexual e os(as) Alunos(as) Com Deficiência: O Que Pensam os(as) Professores(as)?. Dissertação (Mestrado em Psicologia) - Faculdade de Ciências, Universidade Estadual Paulista "Júlio de Mesquita Filho". Bauru, 2020 (em andamento).

FRANÇA-RIBEIRO, H. C. Direitos sexuais e pessoas com deficiência: conquistas e impasses. In Ribeiro, P.R.M.; Figueiró, M.N.D. (Orgs.), Sexualidade, cultura e educação sexual: propostas para reflexão. (p.9-65). São Paulo: Cultura Acadêmica, 2004.

GESSER, M.; NUEMBERG, A. H. Psicologia, Sexualidade e Deficiência: novas perspectivas em Direitos Humanos. Revista Ciência e Profissão, v.34 (4), p.850-863, 2014.

KAUFMAN, M., SILVERBERG, C.; ODETTE, F. The ultimate guide to sex and disability For all of us who live with disabilities, chronic pain e illness ( $2^{\underline{a}}$ ed). Califórnia/USA: Cleis Press, 2003.

MAIA, A.C.B.,; ARANHA, M.S.F. Relatos de professores sobre manifestações sexuais de alunos com deficiência no contexto escolar. Interação (Curitiba), 9(1), p.103-116, 2005.

MAIA, A,C.B.; REIS-YAMAUTI, V.L.; SCHIAVO, R.A.; CAPELLINI, V.L.M.F.; VALLE, T.G.M. Teacher opinions on sexuality and Sexual Education of students with intelectual disability. Estudos de Psicologia, v.32(3), p. 427-435, 2015.

MAIA, A.C.B., RIBEIRO, P.R.M. Desfazendo mitos para minimizar o preconceito sobre a sexualidade de pessoas com deficiências. Rev. Bras Educação Especial, v.16, p.169-176, 2010.

MAIA, A.C. B.; RIBEIRO, P. R. M. Educação Sexual: princípios para a ação. Doxa, v. 15(1), p.15-84, 2011.

MAIA, A.C.B.; VILAÇA, T. Concepções de professores sobre a sexualidade de alunos e a sua formação em educação inclusiva. Rev Educação Especial, Santa Maria, v.30 (59), p.669-680, 2017. 
MAIA, A. C. B.; VILAÇA, T. Educação em Sexualidade Para Alunos/As Com Deficiência Em Portugal: Concepções de Professores/As. In: Anais eletrônicos do VII Seminário Corpo, Gênero e Sexualidade, do III Seminário Internacional Corpo, Gênero e Sexualidade e do III Luso-Brasileiro Educação em Sexualidade, Gênero, Saúde e Sustentabilidade. Rio Grande: Editora da FURG, v. 1., p. 1-8, 2018.

MAIA, A.C.B.; VILAÇA, T. Educação em Sexualidade nas escolas em Portugal: análise documental sobre sua trajetória e suas ações. (p. 106-119). In: GUILHERME, W. D. (Org.). A produção do Conhecimento nas Ciências Sociais Aplicadas 2. Ponta Grossa: Atena Editora, 2019a.

MAIA, A.C.B.; VILAÇA, T. Sexualidade e Deficiência: apontamentos sobre a educação sexual na escola inclusiva. (155-312). In: RIZZA, J.C.; MAGALHÃES, J.C.; RIBEIRO, P.R.C.; COSTA, A.L.C. (Orgs). Tecituras- sobre corpos, gêneros e sexualidades no espaço escolar. Rio Grande: Editora da FURG, 2019b.

MATOS, M. G.; REIS, M.; RAMIRO, L.; RIBEIRO, J. P.; LEAL, I. Educação sexual em Portugal: legislação e avaliação da implementação nas escolas. Psicologia, Saúde \& doenças, v. 15, n. 2, p. 335-355, 2014.

MELO, M. R. A sexualidade de estudantes deficientes mentais: experiências de professoras do ensino fundamental em Sergipe. Linhas, UDESC, v. 7, n. 1, p. 1-15, 2007.

MELO, M. R.; BERGO, M. S. A. A. Atuação do professor diante de manifestações da sexualidade nos alunos portadores de deficiência mental. Rev. Bras. Ed. Esp., Marília, v. 9, n. 2, p. 227-236, 2003.

RIBEIRO, J.; PONTES, A.; SANTOS, L. Conceção e implementação de um projeto de educação sexual na turma. Revista Lusófona de Educação, v.23, p.179-198, 2013.

SAMPIERI, R. H.; COLLADO, C. H.; LUCIO, P. B. Metodologia de Pesquisa. 3a ed. São Paulo: McGraw-Hill, 2006.

SPATA, A. Métodos de Pesquisa - ciência do comportamento e diversidade humana. Rio de Janeiro: LTC, 2005.

UNESCO. International technical guidance on sexuality education: an evidenceinformed approach for schools, teachers and health educators. Paris: UNESCO, UNAIDS, UNFPA, UNICEF, WHO, 2009. Disponível em: <http://unesdoc.unesco.org/images/0018/001832/183281e.pdf>. Acesso em 05 Mai 2018.

VILAÇA, T. Perspectiva evolutiva das políticas e práticas de educação sexual na comunidade escolar em Portugal. Doxa, v.17 (1 e 2), p. 245-293, 2013.

VILAÇA, T. A multiple case study based on action-oriented sexuality education: Perspectives of Portuguese teachers. Health Education, v.117(1), p.110-126, 2017. WILKENFELD, B. F.; BALLAN, M. S. Educators attitudes and beliefs towards the sexuality of individuals with developmental disabilities. Sex Disabil, v.29, 351-261, 2011. 